\title{
PERSPECTIVA DOS PROFISSIONAIS DA EDUCAÇÃO E CUIDADORES SOBRE O PROCESSO DE INCLUSÃO ESCOLAR
}

\section{PERSPECTIVE OF EDUCATION PROFESSIONALS AND CAREGIVERS ON THE SCHOOL INCLUSION PROCESS}

\section{PERSPECTIVA DE LOS PROFESIONALES DE LA EDUCACIÓN Y DE LOS CUIDADORES SOBRE EL PROCESO DE INCLUSIÓN ESCOLAR}

\author{
Meriele Sabrina de Souza ${ }^{1}$, Rhillary Lorrayne de Souza ${ }^{2}$, Nayara Cristine Protte de Paula ${ }^{3}$, \\ Patrícia Pinto Braga ${ }^{4}$
}

Como citar esse artigo: Souza MS, Souza RL, Paula NCP, Braga PP. Perspectiva dos profissionais da educação e cuidadores sobre o processo de inclusão escolar. Rev Enferm Atenção Saúde [Internet]. 2021 [acesso em:__]; 10(3):e202129. doi: https://doi.org/ 10.18554/reas.v10i3.4686

\section{RESUMO}

Objetivo: Analisar o processo de inclusão escolar na perspectiva de profissionais da educação do ensino fundamental e de cuidadores de crianças com deficiência. Metodologia: Estudo qualitativo interpretativo. As entrevistas guiadas por roteiro semiestruturado foram submetidas à análise de conteúdo. Resultados: Participaram 43 pessoas. A análise permitiu identificar três categorias: $\mathrm{O}$ conhecimento dos profissionais da educação sobre a deficiência infantil e inclusão escolar; A inclusão para a criança na perspectiva dos profissionais da educação e cuidadores e Mudanças necessárias à inclusão. Conclusão: No cenário de investigação há desafios para uma educação de fato inclusiva. Diante disso identifica-se que os enfermeiros poderiam atuar nos ambientes escolares para contribuir com aspectos que envolvem a inclusão. Além disso, são necessárias mudanças na infraestrutura das escolas; no ensino dos cursos de graduação na área da educação; na concepção sobre deficiência e capacitação dos profissionais envolvidos.

Descritores: Educação especial. Inclusão escolar. Crianças com deficiência. Práticas interdisciplinares.

\footnotetext{
1 Enfermeira e Residente em Saúde da Família pela Universidade Federal de São João del Rei - UFSJ, Divinópolis - Minas Gerais, E-mail: meiresouza296@gmail.com. ORCID: https://orcid.org/0000-0003-29484304. Currículo Lattes: http://lattes.cnpq.br/4971508430252411.

${ }^{2}$ Enfermeira graduada pela Universidade Federal de São João del Rei - UFSJ, Divinópolis - Minas Gerais. Email: rhillarysouza97@gmail.com. ORCID: https://orcid.org/0000-0001-5805-6064. Currículo lattes: http://lattes.cnpq.br/4483221690836947.

${ }^{3}$ Enfermeira graduada pela Universidade Federal de São João del Rei - UFSJ. Residente em Saúde da Família pela Universidade Federal de Juiz de Fora - UFJF, Minas Gerais. E-mail: nayara.protte@ hotmail.com ORCID: https://orcid.org/0000-0001-8009-4606. Currículo lattes: http://lattes.cnpq.br/8603154498851174.

${ }^{4}$ Pós-doutorado em Enfermagem pela Universidade Federal de Minas Gerais - UFMG. Professora Adjunta da Universidade Federal de São João del Rei - UFSJ, Minas Gerais. E-mail: patriciabragaufsj@gmail.com. ORCID: https://orcid.org/0000-0002-1756-9186. Currículo Lattes: http://lattes.cnpq.br/4368396111319469.
} 


\begin{abstract}
Objective: To analyze the process of school inclusion from the perspective of professionals in primary education and caregivers of children with disabilities. Methodology: Qualitative interpretive study. The interviews guided by a semi-structured script were submitted to content analysis. Results: 43 people participated. The analysis made it possible to identify three categories: The knowledge of education professionals about childhood disability and school inclusion; Inclusion for the child from the perspective of education professionals and caregivers and Changes necessary for inclusion. Conclusion: In the research scenario, there are challenges for a truly inclusive education. Given this, it is identified that nurses could work in school environments to contribute to aspects that involve inclusion. In addition, changes to school infrastructure are needed; in teaching undergraduate courses in the field of education; in the concept of disability and training of the professionals involved.
\end{abstract}

Descriptors: Education special. Mainstreaming education. Disabled children. Interdisciplinary placement.

\title{
RESUMEN
}

Objetivo: Analizar el proceso de inclusión escolar desde la perspectiva de los profesionales de educación primaria y de los cuidadores de niños con discapacidad. Metodología: Estudio cualitativo interpretativo. Las entrevistas guiadas por un cuestionario semiestructurado se sometieron a análisis de contenido. Resultados: Participaron 43 personas. El análisis permitió identificar tres categorías: Conocimiento de los profesionales de la educación sobre la discapacidad infantil y la inclusión escolar; Inclusión del niño desde la perspectiva de los profesionales de la educación y de los cuidadores y Cambios necesarios para la inclusión. Conclusión: En el escenario de investigación, existen desafíos para una educación verdaderamente inclusiva. Se considera que los enfermeros podrían trabajar en ambientes escolares para contribuir con aspectos vinculados a la inclusión. Además, es necesario que se realicen cambios en la infraestructura escolar; en la enseñanza de las carreras del área de la educación; en la concepción de discapacidad y en la formación de los profesionales involucrados.

Descriptores: Educación especial. Integración escolar. Niños con discapacidad. Prácticas interdisciplinarias.

\section{INTRODUÇÃO}

A educação inclusiva pode ser compreendida como um conjunto de processos educacionais que, a partir de políticas articuladas, visam impedir qualquer forma de segregação, discriminação e/ou isolamento. A educação é um direito da pessoa com deficiência que objetiva o alcance de seu desenvolvimento máximo nas diversas habilidades comportamentais segundo suas próprias características. ${ }^{1}$
Muitos são os desafios encontrados na atualidade para inserção de crianças com deficiência na escola regular de ensino, tais como: ausência de estrutura física e adaptada nos ambientes, recursos didáticos pedagógicos escassos para este público, desconhecimento pelos educadores das especificidades e necessidades das crianças, ausência de articulação entre profissionais da educação e da saúde, discriminação por parte da comunidade, dentre outras. ${ }^{2}$ 
Há vários fatores que podem contribuir para o aparecimento das deficiências na infância, podem estar relacionados com assistência à mulher durante a gestação, parto e pós-parto, com a desnutrição, doenças transmissíveis, doenças e eventos crônicos, perturbações psiquiátricas, traumas e lesões. Cerca de 70 a $80 \%$ podem ser evitados por ações específicas voltadas para cada contexto. ${ }^{3}$ Por outro lado, há aquelas inevitáveis provenientes de questões hereditárias e todas elas geram repercussões para toda a vida.

Diante disso, as crianças em processo de inclusão escolar apresentam diferentes demandas de saúde o que sinaliza para a pertinência da presença de um profissional da saúde, como o enfermeiro, que compreenda tais necessidades e atue junto com educadores e cuidadores na inclusão escolar. Partimos da premissa que a presença e ações do enfermeiro no ambiente escolar são oportunas e necessárias para dar suporte aos educadores no processo inclusivo. Entretanto há escassez de estudos nacionais sobre a atuação de profissionais da área da saúde na educação inclusiva. ${ }^{4}$

Mediante o exposto, elaborouse o seguinte questionamento: Como se configura o processo de inclusão escolar de crianças do ensino fundamental na perspectiva de profissionais da educação e cuidadores? A pesquisa teve como objetivo analisar o processo de inclusão escolar na perspectiva de profissionais da educação do ensino fundamental e de cuidadores de crianças com deficiência em um município de Minas Gerais.

\section{METODOLOGIA}

Estudo qualitativo interpretativo que buscou o significado, atribuído pelos participantes, às experiências vividas no cotidiano de inclusão escolar de crianças com deficiência utilizando instrumento semiestruturado elaborado pelos pesquisadores considerando o objetivo e o referencial teórico adotado.

Adotamos o referencial teórico de Boa Ventura de Souza Santos que nos convida a sair de um estado de convencimento ou naturalização das diferenças e desigualdades sociais apostando na renovação das teorias críticas e na reemancipação social. Essas transformações se darão por meio de subjetividades que buscam por novas possibilidades de organizar a sociedade, tornando-a mais includente, superando a reificação do presente, sem, contudo, abandonar um projeto de futuro. Nesse sentido o teórico nos convoca a recusar uma lógica do pensamento e das ações na qual não há nada além do que existe, sinalizando para a importância da 
construção de novas formas de pensar e fazer. ${ }^{5}$ Este referencial é pertinente para olhar e analisar o objeto desta investigação por considerar as diversidades de produção de vida existentes no cotidiano, podendo ser expandida para os territórios escolares. Neste sentido com este referencial os pesquisadores reconhecem a deficiência na infância não como uma doença mas como um modo de ser e estar no mundo e que a diferença é parte da constituição da sociedade.

Participaram da pesquisa: dez cuidadores, dez diretores, dez assistentes educacionais e 13 professores, totalizando 43 participantes. O critério para inclusão dos participantes foi ser professor, assistente educacional, diretor e cuidador principal de crianças até dez anos com deficiência física ou múltipla matriculada no ensino fundamental das escolas municipais da cidade de desenvolvimento do estudo. A partir de informações fornecidas pela secretaria municipal de educação e adotando os critérios de inclusão, 14 crianças seriam selecionadas para participarem da pesquisa, porém uma das mães não possuía tempo disponível para a realização da entrevista, e uma das escolas não conseguiu identificar a criança. Sendo assim, foram entrevistados profissionais de dez escolas.

A entrevista semiestruturada foi conduzida buscando informações sobre como é o cotidiano de cuidados à criança, como foi o processo de inclusão, quais os desafios e facilidades encontrados, como os participantes percebem atualmente a inclusão da criança na escola, quais as estratégias estão sendo planejadas e realizadas para favorecer esse processo no município e como acontece a articulação com a família e profissionais dos serviços de saúde.

Após a realização das entrevistas estas foram transcritas na íntegra e com o propósito de preservar a identidade dos participantes, foi estabelecido o código "E" para “entrevistado" seguido por "A", "P”, "D” e "C" para assistente educacional, professores, diretores e cuidadores respectivamente. Foi designado para cada entrevistado a sequência numérica de acordo com a realização das entrevistas variando de um a treze para os professores e de um a dez para as demais categorias participantes. Utilizou-se a codificação em toda a organização e análise do estudo mantendo a mesma ordem.

Os dados coletados foram submetidos à análise de conteúdo. ${ }^{6} \mathrm{Na}$ fase inicial, denominada pré-análise, o material foi organizado com as transcrições de todas as entrevistas permitindo um primeiro contato com os textos. Posteriormente, realizou-se a leitura flutuante das entrevistas, captando o 
conteúdo genericamente. Já na segunda etapa, após leitura sucessivas e repetidas, foi realizada a referenciação dos índices e a elaboração de indicadores com recortes do texto o que favoreceu a categorização. A categorização foi um processo de agrupamento de ideias por semelhança para permitir a apresentação de núcleos de sentidos. E por fim, foi implementada a terceira etapa, na qual desenvolveu-se a interpretação dos dados com bibliografia pertinente.

A pesquisa foi desenvolvida atendendo ao disposto na resolução $466 / 2012$ que trata de pesquisas envolvendo seres humanos. Foi aprovada pelo Comitê de ética da instituição proponente conforme o número $\mathrm{CAAE}$ 74009317.1.0000.5545. Antes da realização das entrevistas e aplicação dos questionários, os participantes concederam a autorização para participação mediante aceite e assinatura do Termo de Consentimento Livre e Esclarecido e receberam uma via deste documento.

\section{RESULTADOS E DISCUSSÕES}

Os cuidadores participantes da pesquisa eram todos do sexo feminino, somente uma era avó da criança, a idade variou de 26 a 66 anos, a maioria residia em casa própria com renda entre um a dois salários mínimos. Em relação a escolaridade $60 \%$ não possuíam o ensino médio, $20 \%$ possuíam o ensino médio completo e $20 \%$ o superior completo. Os profissionais da educação possuíam idade entre 20 e 62 anos, a maioria era do sexo feminino, com tempo de atuação entre um a dez anos e do total, cinco estavam em estágio, ou seja, na graduação.

A análise do conteúdo das entrevistas permitiu identificar três categorias: $\mathrm{O}$ conhecimento dos profissionais da educação sobre a deficiência infantil e inclusão escolar; A inclusão para a criança na perspectiva dos profissionais da educação e cuidadores e Mudanças necessárias à inclusão.

\section{Conhecimento dos profissionais da} educação sobre a deficiência infantil e a inclusão escolar

A análise sinaliza que a maioria dos profissionais da educação entrevistados não recebeu subsídios teóricos e práticos sobre a inclusão e/ou deficiência na infância durante a graduação. $\mathrm{O}$ conhecimento acerca do processo de inclusão escolar, no cenário de investigação, acontece a partir da experiência e convivência com a criança no cotidiano de trabalho. Frente à diversidade e peculiaridades das deficiências os profissionais buscam o conhecimento de acordo com a demanda, por meio da internet, realização de cursos e troca de experiências com colegas de 
trabalho. Uma das dificuldades apresentadas pelos entrevistados da educação é o não conhecimento sobre a deficiência, necessidades ou demandas que a criança possui. Estas evidências são exemplificadas nos enunciados a seguir:

$$
\text { ED1- Eu não tenho muito }
$$

conhecimento porque eu não tive né, quando eu me formei não tinha a disciplina que trabalhava a inclusão, ensinava a trabalhar com a inclusão. Então o meu conhecimento, foi porque eu já trabalhei em sala de aula com alunos que tinham né, algumas dificuldades, aî eu busquei ler um pouco e tudo, mas as deficiências são diversas né, então tem algumas que eu não tenho muito conhecimento ainda. EP2- Apesar que o papel é uma coisa, a prática é outra coisa. Você aprende mexendo. Mas você tem que ter o conhecimento pra você saber como que você vai agir em determinadas situações.

Um dos principais desafios da inclusão escolar está relacionado ao processo de formação dos profissionais, estes não estão sendo capacitados para trabalhar com a criança com deficiência nem para inseri-la no contexto da sala de aula. Durante a formação dos professores há carência de atuação com alunos com deficiência, desencadeando uma atuação sem preparo, seja ela prática ou teórica. ${ }^{4}$ Para que o educador reconheça as demandas de saúde e cuidados específicos das crianças, é necessário ação interprofissional. Nesse sentido, recomenda-se a atuação intersetorial do enfermeiro na escola com vistas a promoção da saúde e prevenção de agravos, realizando capacitações de modo que os profissionais da educação sejam preparados para reconhecer e lidar com as necessidades de saúde no cotidiano escolar.

Apesar de identificarmos escassez na formação dos profissionais entrevistados inferimos que isso não deve se tornar justificativa para reprodução de um discurso de inviabilidade, como dito por EP1. Devemos, como nos convida o referencial, ressignificar esta realidade buscando estratégias práticas e conhecimentos teóricos que nos permitam cotidianamente criar o novo e contribuir de fato para o reconhecimento e legitimação da cidadania e inclusão social destas crianças. $^{5}$

A análise revelou também que os profissionais da educação percebem um aumento do número de crianças com deficiência, nos últimos anos, nas escolas nas quais trabalham. Relacionam esse crescimento com o fato das crianças não serem mais encaminhadas para as escolas especiais e sim matriculadas nas escolas regulares de ensino, como pode ser verificado no enunciado a seguir:

ED3- Bom, a deficiência hoje tá numa escala muito maior do que assim, eu tenho catorze anos de profissão em sala de aula, e eu observo que nos últimos cinco anos, a gente tinha um, dois, eu não sei também se é por causa dessas crianças estarem vindo na escola regular, porque 
até então elas tinham uma instituição que atendiam elas, talvez esteja percebendo por isso, que elas tinha uma instituição que atendia e hoje a escola regular recebe essas crianças.

Estatísticas do Instituto Nacional de Estudos e Pesquisas Educacionais Anísio Teixeira (2014), apontam um crescimento significativo na matrícula de alunos em educação especial na escola regular. Dados do resumo técnico do censo escolar, de 2013, registraram em 2007, 306.136 matrículas de estudantes apoiados pela Educação Especial na Educação Básica e em 2013, 648.921 alunos. ${ }^{7}$ Contudo não existem dados consistentes sobre a deficiência infantil no Brasil, o que dificulta uma análise confiável e inferências sobre o acesso deste público à escola, tão pouco permite afirmar se de fato estas crianças estão incluídas ou apenas presentes nos espaços escolares.

$\mathrm{O}$ conhecimento que os profissionais possuem sobre as deficiências na infância é que elas são diversas, suas causas são relacionadas a vários fatores e cada uma tem suas especificidades. Isso demanda que o profissional educador desenvolva trabalhos diferenciados considerando essas peculiaridades, processo este que pode ser facilitado em trabalho conjunto com o enfermeiro levando ao aperfeiçoamento pedagógico e aprendizagem integrada do aluno. Os profissionais também relatam a dificuldade da aceitação das deficiências não aparentes, como a deficiência intelectual, Transtorno do Espectro Autista (TEA), e outras. Afirmam que essas deficiências são as mais comuns e que representam desafios no processo de inclusão escolar. Quanto às causas da deficiência na infância, relacionam estas ao aparecimento de complicações durante a gestação, uso de drogas e problemas genéticos.

EPl- Eu vejo como... Algo que aconteceu durante a gestação... Como algo genético, como princípios de, é... Aborto, uma gravidez conturbada. Porque são vários tipos de deficiência né, nem sempre tá ligado à genética, a maioria tá ligado à gestação, a... A princípio de aborto, aquela, é... Rejeição. EA2- Então, assim... Existem diversas deficiências né, e cada criança apresenta a sua peculiaridade, então... Assim... é muito importante que se desenvolva trabalhos né, voltados para cada tipo de deficiência que a criança apresenta. EP7- (...) como educadora, a gente, eu vejo que as pessoas têm uma falsa visão da deficiência, porque quando se fala em deficiência as pessoas pensam só naquilo que é aparente né, e a gente lida exatamente com o outro lado, aquele que não se vê.

A fala de EP7 demonstra a importância da percepção do educador quanto ao desempenho de seus alunos dentro da sala de aula, para a identificação precoce de deficiências não aparentes e o devido encaminhamento para profissionais da saúde. A escola possui um papel relevante no processo diagnóstico quando os educadores alertam os pais sobre atrasos 
no processo de aprendizagem de seus filhos. Entretanto há maior resistência da família em aceitar um diagnóstico quando este não apresenta marcadores biológicos. ${ }^{8}$ Isso fundamenta a importância da presença do enfermeiro no ambiente escolar que poderia contribuir para o diagnóstico precoce.

\section{A inclusão para a criança na perspectiva} dos profissionais da educação e familiares

Os profissionais da educação afirmam a importância da inclusão para o desenvolvimento das crianças à medida em que o convívio com outras crianças no ambiente escolar pode ser considerado uma forma de estímulo. A análise revela um reconhecimento da evolução da criança em suas habilidades motoras, sociais e na alfabetização.

ED4- Eu acho, eu penso que pra nós aqui da escola municipal (...) os avanços é conseguir com que essas crianças, muitas delas né, com deficiência que anteriormente teriam prognóstico de dificuldade de se alfabetizarem, essas crianças conseguem se alfabetizar... EP5Quando o aluno tá só na escola especial, que é ele tá só entre seus iguais, o desenvolvimento é muito menor. Cognitivo, afetivo, social... Fica tudo muito limitado. Quando ele tá junto das crianças típicas, é... Acho que por vivenciar alguém que tá assim, que, que... Não sei se a palavra é essa, que a criança tem mais capacidade, sabe? Que a criança vê alguém que tá além do seu limite, a criança desenvolve, porque ela tenta chegar até lá. O objetivo dela passa a ser uma coisa maior. Um estímulo maior pra ela.

A inclusão escolar propicia o contato entre as crianças, o que pode minimizar o preconceito e auxiliar na formação de uma sociedade menos excludente. Por isso pode ser vista como benéfica não só para a criança da educação inclusiva, mas para todos os atores da comunidade escolar: os demais estudantes, professores, diretores, pais de alunos e funcionários da escola. Os profissionais relatam sentimento de crescimento ao observarem, no cotidiano do processo de aprendizagem, o desenvolvimento das crianças. $^{9}$

A socialização é tema de destaque quando se discute a inclusão escolar. Para alguns profissionais, várias crianças estão na escola para vivenciarem o lado social e acabam conseguindo adquirir habilidades através dessa convivência. As principais dificuldades estão relacionadas com as crianças que possuem transtorno do espectro autista, devido às características do transtorno, e também aquelas com comportamentos agressivos. Em meio a essas diferenças, destacam-se a aceitação dos colegas de sala em relação à criança; eles se adaptam facilmente e não manifestam resistência à diferença.

ED4- A questão da socialização que nós sabemos hoje, que não se dá só dentro da 
escola, né, mas a escola é importante nesse fator de socialização. Então nós percebemos essa criança bem socializada, percebemos é... A satisfação da família em estar na escola conosco. EP5- Eu tenho crianças autistas, é... Com Síndrome de Abstinência Fetal que não conseguem socializar, porque aí agem de forma agressiva, os colegas não querem que aproxime. E isso eu vejo assim, com um, um dificultador muito grande pro meu trabalho.

A socialização, entretanto, não deve ser considerada como único objetivo deixando-se o processo de aprendizagem em último plano. Muitas vezes os alunos com deficiência, que são considerados como incapacitados de adquirir conhecimentos ou apresentam dificuldades de inserção no currículo escolar, acabam sendo conduzidos a vivenciar experiências com foco na convivência/sociabilidade. Por isso, deve-se valorizar a socialização, mas, não adotá-la como prioridade no processo de inclusão escolar independentemente de qualquer motivo. ${ }^{10}$

Os cuidadores também mencionam as facilidades e dificuldades encontradas na socialização e alfabetização das crianças. Essa última é permeada por incertezas quanto à capacidade da criança e fascínio perante o desenvolvimento de alguma habilidade. Apesar das dificuldades no processo de aprendizagem há algum êxito, no qual eles destacam o papel do Atendimento Educacional Especializado (AEE) e do Assistente Educacional como pode ser verificado a seguir:
EC8- Bem, a questão da socialização depois que ele entrou na escola com um ano $e$ pouquinho, ele foi, ele ficou bem mais sociável, ele não estranha ninguém, é... ele participa das mesmas atividades que eu. EC2- Tem a professora de apoio, né? Que é um trabalho muito bom, que ela... Como ele não tem problema neurológico, então ela fica mais pra locomoção, para pegar alguma coisa pra ele, entendeu?

Os cuidadores entrevistados expressam uma percepção positiva acerca do processo de inclusão e expressam satisfação com a assistência fornecida a seus filhos, com os profissionais envolvidos, e com o processo de socialização. Estudos encontraram resultados semelhantes no que diz respeito as expectativas dos pais em relação ao processo de inclusão escolar. ${ }^{11,12}$ Grande parte dos pais afirmaram boas experiências no processo de inclusão, com expectativas voltadas ao processo de aprendizagem, como a alfabetização.

\section{Adaptações e mudanças necessárias à inclusão}

Apesar dos recursos disponíveis para as crianças com deficiência os profissionais afirmam que são poucos os avanços. Mencionam a falta e/ou inadequada infraestrutura; despreparo da escola em receber esses alunos em salas de aula com número elevado de estudantes e falta de material adequado. Assim, há necessidade de investimentos tanto para 
adaptações físicas como para recursos humanos, além da adaptação de material pedagógico, que constitui a principal estratégia para a alfabetização e ensino da criança com deficiência e um desafio para os profissionais que lidam diretamente com o ensino, como evidenciado nos discursos a seguir:

EP3- Eu acho que a questão assim, a escola, é o que eu falei, não tá preparada. A questão assim de acessibilidade, sabe? De... Até o próprio material, é, adequado, né. As escolas não estão preparadas, por mais que o professor, por mais que, venha né, investindo nessas coisa, não está ainda preparado pra isso. ED1- Tem o caso da assistente educacional, que não são todas as crianças que têm, muitas delas têm estagiário, o estagiário não têm conhecimento pra trabalhar com essas crianças. Às vezes a criança tá lá, o estagiário que vem pra gente ele tá fazendo educação física a distância, tá no primeiro período. Ele não, ele nunca nem ouviu falar de inclusão. Ele vem aqui pra assistir essas crianças né.

No cenário da pesquisa os auxiliares educacionais são, normalmente, estagiários que cursam diferentes cursos de graduação da área da educação. É possível constatar que alunos em processo de graduação que não possuem contato com a temática relativa à inclusão escolar sentemse despreparados para a realidade que enfrentam junto aos alunos em inclusão. A função do estagiário que trabalha com estes alunos é de oferecer apoio ao professor, entretanto o que se observa é que são transferidas para estes responsabilidades que fogem de suas atribuições e que recebem pouco suporte para a função que desempenham. ${ }^{13}$

A fala de ED3 expressa que o número elevado de alunos por sala dificulta o processo de trabalho com o aluno em inclusão. Essa superlotação também pode ser observada em todo o país, e quando aliado a uma infraestrutura inadequada é capaz de interferir diretamente no processo de ensinoaprendizagem dos estudantes. ${ }^{14} \mathrm{~A}$ ausência ou inadequada acessibilidade, dentro ou fora das escolas, é uma realidade no cenário de investigação. Isso evidencia a necessidade de uma equipe multiprofissional para adequações arquitetônicas e mobiliárias que facilitem o dia-a-dia da criança com deficiência. ${ }^{15}$

\section{CONSIDERAÇÕES FINAIS}

Os desafios que permeiam o processo de inclusão escolar no cenário de investigação variam desde a necessidade de adequação do espaço físico das escolas até a capacitação dos profissionais envolvidos no processo, aumento no número de assistentes educacionais, adequação da matriz curricular dos cursos de graduação na área da educação, mudança na concepção sobre deficiência e aprendizado por parte de alguns profissionais. Apesar disso, há conquistas, como o direito da criança com deficiência 
à inserção nas escolas regulares de ensino, a boa aceitação das crianças pelos colegas de classe e a não exclusão por eles, contribuindo para diminuição da discriminação e estigmatização deste público.

Os resultados desta investigação apontam que a criação de espaço de encontros nas escolas, e uma aproximação envolvendo os profissionais das áreas da saúde, família e educação seria uma conquista no processo de inclusão, pois possibilitaria discussões em grupo com troca de saberes a fim de atender as demandas das crianças em diferentes aspectos além de favorecer melhor compreensão das diferentes deficiências que se apresentam e quais seriam as possibilidades de desenvolvimento para cada criança. Dessa forma com uma articulação oportuna entre o pedagógico e aspectos clínicos as crianças da educação inclusiva teriam a possibilidade de alcançar desenvolvimento com maior qualidade e êxito. Isso evidencia a importância dos enfermeiros atuarem no ambiente escolar em articulação com os profissionais da educação.

A presente pesquisa contribuiu para revelar como tem se configurado o processo de inclusão escolar no cenário de investigação, mas cabe mencionar a existência de limitações no estudo como a falta de articulação entre os dados fornecidos pela secretaria municipal de educação e a identificação da matricula na escola para localização do aluno, disponibilidade de horário do cuidador incompatível com os horários disponibilizados pelos pesquisadores e a restrição de coletas de dados a somente um município e em escolas públicas, não sendo incluídos serviços privados o que permitiria análises complementares.

\section{REFERÊNCIAS}

1. Presidência da República (Brasil). Lei ${ }^{\circ}$ 13.146, de 6 de julho de 2015.

Institui a Lei Brasileira de Inclusão da Pessoa com Deficiência (Estatuto da Pessoa com Deficiência) [Internet]. Diário Oficial da União, Brasília, DF, 7 jul 2015 [citado 03 jun 2020]. Disponível em: http://www.planalto.gov.br/ccivil_03/_ato2 015-2018/2015/lei/113146.htm

2. Mello ARL. Refletindo sobre a inclusão escolar brasileira. J Res Spec Educ Needs [Internet]. 2016 [citado em 03 jun 2020]; 16(1):931-35. Disponível em: https://nasenjournals.onlinelibrary.wiley.co m/doi/epdf/10.1111/1471-3802.12234

3. Ministério da Saúde (Brasil), Secretaria de Atenção à Saúde, Departamento de Ações Programáticas e Estratégicas. Política Nacional de Atenção Integral à Saúde da Criança: orientações para implementação [Internet]. Brasília, DF: Ministério da Saúde; 2018 [citado em 03 jun 2020]. 180 p. Disponível em: https://portaldeboaspraticas.iff.fiocruz.br/w pcontent/uploads/2018/07/Pol\%C3\%ADtic a-Nacional-de-Aten\%C3\%A7\%C3\%A3oIntegral-\%C3\% A0-Sa\%C3\%BAde-daCrian $\%$ C3\%A7a-PNAISCVers\%C3\%A3o-Eletr\%C3\%B4nica.pdf 4. Silva NC, Carvalho BGE.

Compreendendo o processo de inclusão 
escolar no Brasil na perspectiva dos professores: uma revisão integrativa. Rev Bras Educ Espec. [Internet]. abr/jun 2017 [citado em 03 jun 2020]; 23(2):293-308. Disponível em:

https://www.scielo.br/j/rbee/a/5QWT88nT KPL4VMLSGRG7dSM/?format=pdf\&lan $\mathrm{g}=\mathrm{pt}$

5. Santos BS. A Gramática do tempo: para uma nova cultura política. 3ed. São Paulo: Editora Cortez; 2006.

6. Bardin L. Análise de conteúdo. 4ed. Lisboa: Edições 70; 2008.

7. Instituto Nacional de Estudos e Pesquisas Educacionais Anísio Teixeira. Censo escolar da educação básica 2013: resumo técnico [Internet]. Brasília, DF: INEP; 2014 [citado em 03 jun 2020]. 39 p. Disponível em:

https://download.inep.gov.br/educacao_bas ica/censo_escolar/resumos_tecnicos/resum o_tecnico_censo_educacao_basica_2013.p df

8. Ferreira FGC. A negociação do diagnóstico de autismo. [monografia]. Porto Alegre, RS: Universidade Federal do Rio Grande do Sul; 2015 [citado em 03 jun 2020]. 49 p. Disponível em: https://lume.ufrgs.br/handle/10183/132351

9. Oliva DV. Raízes sociais e psicodinâmicas do preconceito e suas implicações na educação inclusiva. Psicol Esc Educ. [Internet]. maio/ago 2016 [citado em 03 jun 2020]; 20(2):349-56. Disponível em:

https://www.scielo.br/j/pee/a/s835LNfBDn F7rFP57c7J3sx/?format=pdf\&lang=pt 10. Viera $A B$, Ramos IO. Diálogos entre Boaventura de Sousa Santos, Educação Especial e Currículo. Educ Real. [Internet]. jan/mar 2018 [citado em 03 jun 2020]; 43(1):131-51. Disponível em: https://www.scielo.br/j/edreal/a/zMbNbtG xpvLyyxL98bmz4wz/?format=pdf\&lang= $\mathrm{pt}$

11. Lemos ELMD, Salomão NMR, Aquino FSB, Agripino-Reamos CS. Concepções de pais e professores sobre a inclusão de crianças autistas. Fractal Rev Psicol. [Internet]. set/dez 2016 [citado em 03 jun 2020]; 28(3):351-61. Disponível em: https://www.scielo.br/j/fractal/a/qc5nWBR r7JCCmHTNb3XQShv/?format=pdf\&lang $=\mathrm{pt}$

12. Coelho GR, Campos JAPP, Benitez P. Relato de pais sobre a inclusão e a trajetória escolar de filhos com deficiência intelectual. Psicol Rev. (Belo Horizonte) [Internet]. jan 2017 [citado em 03 jun 2020]; 23(1):22-41. Disponível em: http://periodicos.pucminas.br/index.php/psicol psicologiaemr/article/view/6555/1263113 13. Vicente BT, Bezzera GF. Estagiários e professores regentes como agentes do processo de inclusão escolar: problematizando suas (inter)ações. Rev Linhas [Internet]. set/dez 2017 [citado em 03 jun 2020]; 18(38):214-44. Disponível em:

https://www.revistas.udesc.br/index.php/li nhas/article/view/1984723818382017214/p df

14. Garcia PMA, Diniz RF, Martins MFA. Inclusão escolar no ensino médio: desafios da prática docente. Rev Ibero-Am. Estud Educ. [Internet]. 2016 [citado em 03 jun 2020]; 11(n. esp. 2):1000-16. Disponível em:

https://periodicos.fclar.unesp.br/iberoameri cana/article/view/8939/5882

15. Melo FRLV, Lucena NMG, Saraiva LLO. Atuação de fisioterapeutas na inclusão de alunos com deficiência no ensino regular. Educ Quest. [Internet]. jul/set 2017 [citado em 03 jun 2020]; 55(45):176-199. Disponível em: https://periodicos.ufrn.br/educacaoemquest ao/article/view/12750/8782

RECEBIDO: $19 / 06 / 2020$

APROVADO: $21 / 03 / 2021$

PUBLICADO: dez/2021 